\title{
TRAJETÓRIAS TECNOLÓGICAS NO SEGMENTO OFFSHORE: AMBIENTE E OPORTUNIDADES ${ }^{*}$
}

\author{
José Benedito Ortiz Neto ${ }^{* *}$ \\ Walter Tadahiro Shima ${ }^{* * *}$
}

\begin{abstract}
RESUMO Este artigo apresenta as diferentes trajetórias tecnológicas do segmento offshore na indústria petrolífera mundial considerando os seus principais aspectos e marcos constituintes. Mais especificamente, serão analisadas as trajetórias diferentes nas duas primeiras grandes províncias de petróleo do segmento offshore: o Golfo do México (EUA) e o Mar do Norte (Europa). Junto com a Bacia de Campos (Brasil), são as mais produtivas e ricas do planeta e onde as três trajetórias tecnológicas foram desenvolvidas. Esse levantamento histórico é importante porque resgata os elementos que dão as bases do conhecimento tecnológico que permitiu à Petrobras, de forma inédita, iniciar as suas atividades offshore nas décadas de 1960-1970. Será visto aqui que a exploração offshore significou o surgimento de um novo paradigma tecnológico sustentado por três trajetórias.
\end{abstract}

Palavras-chave: Petrobras; aprendizado; offshore; trajetórias tecnológicas; oportunidades

Código JEL: O33 - Technological change: choices and consequences; diffusion processes

* Artigo recebido em 12 de fevereiro de 2007 e aprovado em 6 de agosto de 2008.

** Mestre em Desenvolvimento Econômico pelo Programa de Pós-graduação em Desenvolvimento Econômico da Universidade Federal do Paraná, e-mail: netolon@yahoo.com.br

*** Professor do Programa de Pós-graduação em Desenvolvimento Econômico da Universidade Federal do Paraná, e-mail: waltershima@ufpr.br 


\section{TECHNOLOGICAL TRAJECTORIES IN THE OFFSHORE SEGMENT: ENVIROMENT AND OPPORTUNITIES}

ABSTRACT This article presents different technological trajectories concerning the offshore exploration segment in the world petroleum industry, considering their main aspects and components. More specifically, different trajectories will be analyzed in the first two largest crude oil territories: Gulf of Mexico (USA) and Sea North (Europe). These, along with Bacia de Campos in Brazil, are the most productive and the richest regions in the planet and, therefore, where the three technological trajectories have been developed. This historic survey is important because it reveals the elements that provide the basis for technological knowledge, which allowed Petrobras to start its offshore activities in the 60s and 70s, via an original technology. The offshore exploration meant the emergence of a new technological paradigm supported by three trajectories.

Key words: Petrobras; learning; offshore; technological trajectories; opportunities 


\section{INTRODUÇÃO}

O objetivo deste artigo é discutir o surgimento de diferentes trajetórias tecnológicas que sustentam um novo paradigma tecnológico, que é a exploração offshore na indústria petrolífera mundial, considerando os seus principais aspectos e marcos de natureza institucionais constituintes. Mais especificamente, analisaremos as trajetórias diferentes nas duas primeiras grandes províncias de petróleo do segmento offshore: o Golfo do México (EUA) e o Mar do Norte (Europa). Consideramos que essas duas, juntamente com a Bacia de Campos (Brasil), são as mais produtivas e ricas do planeta e onde as três trajetórias tecnológicas foram desenvolvidas. Esse é um levantamento histórico da estrutura e conjuntura que definem o desenvolvimento tecnológico, e torna-se importante porque resgata os elementos que dão as bases do conhecimento tecnológico que permitiu à Petrobras, de forma inédita, iniciar as suas atividades offshore nas décadas de 1960-1970.

A exploração offshore teve início no final do século XIX, em águas ultrarasas (swallow water - até 30 metros), de maneira bastante rudimentar e de forma pouco científica. Isso porque as dificuldades tecnológicas offshore eram superadas de maneira empírica, apenas por learning-by-trying e com apoio de pesquisa e desenvolvimento (P\&D) dedicado. Na verdade, era transferido para a exploração offshore o mesmo padrão tecnológico utilizado no segmento onshore (em terra). Apenas com a ampliação das descobertas e o conseqüente aumento das dificuldades de exploração em campos mais profundos (águas rasas - entre 30 e 400 metros) e mais distantes da costa, foi necessário o desenvolvimento de procedimentos e tecnologias próprias, não sendo mais utilizada a rudimentar e empírica adaptação de equipamentos onshore. Iniciava-se assim a busca de uma trajetória tecnológica que viabilizasse a exploração offshore em mar aberto.

Dessa forma, com os muitos avanços da P\&D em diversas áreas do conhecimento que são convergentes, pôde-se chegar aos campos ultraprofundos (mais de 1.500 metros) na década de 1990. Tais avanços ocorreram em três grandes áreas tecnológicas, reconhecidas como big tree: sísmica; perfuração e plataformas com seus equipamentos (Miles, 2005; Austin et al., 2004). 
Nesta última área, de plataformas e equipamentos, ao longo do século XX a P\&D deu origem a três trajetórias tecnológicas: Sistema Rígido (ou fixo) de Produção (SRP), Sistema Flexível (ou híbrido) de Produção (SFP) e Sistema de Produção Flutuante (SPF). As características diferenciais básicas de cada sistema são as estruturas de sustentação das plataformas:

SRP = uma estrutura sólida ligando a plataforma até o leito marinho, mas sem nenhuma estrutura de flutuação;

SFP = uma estrutura flexível (cabos de aço entrelaçados) liga a plataforma até o leito e a plataforma flutua com o auxílio de bóias;

SPF = não existe uma estrutura de ligação da plataforma com o leito marinho, mas sim uma estrutura de ancoragem. O SPF é representado por plataformas semi-submersíveis de produção (SS-FPU - Semi-submersible Floating Production Unit) e barcos do tipo FPSO (Floating Production Storage and Offshoring), os quais foram amplamente difundidos na Bacia de Campos do Brasil.

Com essas disponibilidades de soluções tecnológicas para a exploração offshore houve um aumento significativo no volume total de hidrocarbonetos disponíveis a ser prospectado. Por conta disso, atualmente aproximadamente $30 \%$ da produção mundial de petróleo e gás passaram a ser provenientes das bacias sedimentares submersas nas mais diversas províncias submarinas (Miles, 2005; Noia, 2005).

A seguir, na seção 1 exporemos os elementos de natureza teórica que fundamentam o texto, mostrando a importância das instituições na definição de trajetórias tecnológicas. Entendemos que a dinâmica das inovações é fortemente marcada pelo caminho das instituições, na medida em que elas definem claramente as regras de comportamento do mercado. Nas seções 2 e 3 serão analisadas as trajetórias, nas duas primeiras e mais importantes províncias de petróleo do mundo: o Golfo do México e o Mar do Norte, mostrando que os EUA eram os únicos a produzir petróleo em águas até a década de 1960 em escala comercial e que a partir de então surge uma nova trajetória no Mar do Norte. As seções 4, 5 e 6 demonstram a evolução mundial e do Brasil no segmento offshore através dos avanços tecnológicos. Por fim, as conclusões. 


\section{Alguns elementos RELEVANTES NORTEAdores}

Temos três elementos teórico-metodológicos que norteiam este artigo que exporemos brevemente a seguir e que serão destacados ao longo do texto.

O primeiro deles é o conceito de paradigma tecnológico, em que se insere também a noção de trajetórias tecnológicas. Segundo Dosi (1982), um paradigma se refere a um conjunto de conhecimentos práticos e teóricos, métodos, procedimentos, heurísticas, experiências de sucessos e falhas, além de equipamentos e materiais que incorporam parte das realizações passadas na solução de determinados problemas. Esse conjunto de conhecimentos e objetos tem uma estrutura e uma organização. Sendo assim, estabelecem-se dentro do paradigma normas sobre a direção da mudança técnica a ser buscada, assim como sobre as direções que devem ser evitadas. Isso significa que há fortes efeitos de exclusão em que os esforços de aprendizado e as inovações geradas assumem uma direção muito clara, de tal forma que bloqueia outras possibilidades tecnológicas. Em determinado paradigma, define-se trajetória tecnológica como o padrão normal das atividades de resolução de problemas com base nas possibilidades preestabelecidas pelo paradigma. Em outros termos, um paradigma tecnológico estabelece os limites por onde a trajetória tecnológica pode caminhar. Trata-se de um conjunto de possíveis direções tecnológicas cujas fronteiras são delimitadas pela natureza do paradigma em questão.

Tendo isso em conta, pretendemos discutir que a exploração offshore se refere ao paradigma, e as diversas formas de sua exploração desenvolvidas nas diversas regiões do planeta correspondem às trajetórias tecnológicas, uma vez que elas estão circunscritas a determinados limites estabelecidos pela natureza das próprias tecnologias offshore. Assim sendo, destacamos que temos claro que um paradigma ou uma determinada trajetória não se estabelecem espontaneamente a partir de um mapa de indiferenças e caminhos de expansão (demand-pull), nem por relação de causalidade entre o desenvolvimento científico e o progresso tecnológico, independentemente dos aspectos econômicos (technology-push).

Mais do que isso, entendemos que o paradigma se estabelece ou se desenvolve complementarmente com os determinantes institucionais do processo de inovação. As instituições correspondem ao nosso segundo elemen- 
to teórico-metodológico. Instituições são entendidas em um sentido mais amplo de regras do jogo, em uma dimensão comportamental, como as normas, crenças e convenções, atuando como restrições do ponto de vista da sociabilidade humana, como também em um sentido restrito, referindo-se a entidades físicas, que também atuam sob determinadas normas. Portanto, desenvolvimento tecnológico e instituições são elementos fortemente integrados que se explicam mutuamente. Em outros termos, as fundamentações institucionalistas que têm um foco maior na dimensão do comportamento e regras de direção em condições de incerteza se complementam com a abordagem neo-schumpeteriana que tem um foco maior na dimensão produtivo-inovadora. Mostraremos que o desenvolvimento de trajetórias tecnológicas offshore estará fortemente condicionado e acompanhado pelo desenvolvimento de instituições. Seria impossível entender que essas trajetórias pudessem ter algum sucesso não fosse a percepção pelos países da necessidade do desenvolvimento de institutos de P\&D e normas regulatórias para a prospecção e exploração de petróleo.

Por último, destacamos o conceito de ambiente de seleção, que também se circunscreve ao paradigma. Este é entendido como os elementos exógenos à firma que influenciam seu comportamento e estratégias. É o conjunto de elementos que orientam, ex ante, o processo de busca das empresas do que é ou não economicamente rentável e que, ex post, validam (ou não) as escolhas efetuadas. Para isso a firma detém algum grau de racionalidade que cria suas expectativas em função da rotina do ambiente e, conseqüentemente, orienta a criação das suas estratégias. Os elementos constitutivos do ambiente são: a oportunidade (exploração de atividades que se relacionam com o paradigma tecnológico); a apropriabilidade (a oportunidade implica apropriável e não imitável); a cumulatividade (a firma estabelece a direção do progresso técnico e concentra atividades nesse padrão); e as características da base relevante de conhecimentos (a firma possui um conjunto de conhecimentos tácitos de caráter privado, que se adquirem pela capacidade cognitiva do agente e são não codificáveis, pois são incorporados nas pessoas e organizações; portanto, são coletivos) (Baptista, 2000). Veremos que os elementos ambientais relativos a cada trajetória offshore desenvolvida estabelecerão condições e conseqüentes resultados tecnológicos diferentes. Daí se explicam as diferentes trajetórias. 


\section{A PRIMEIRA TRAJETÓRIA TECNOLÓGICA: SRP A PARTIR DO GOLFO DO MÉXICO}

Pode-se ter como marco inicial da produção offshore, de forma bastante rudimentar, a que ocorreu no condado de Santa Bárbara, Califórnia/Estados Unidos, em 1896. O primeiro poço tinha uma profundidade de quase 6 metros e ficava a uma distância aproximada de 15 metros da praia, tendo sido explorado pela transferência e adaptação das condições onshore para as condições em água. Desse modo, não se tratava de plataformas de produção, mas sim de um conjunto de cavaletes seqüencialmente instalados a partir de uma estação em terra. Nesses cavaletes eram instaladas bombas de prospecção e dutos para transportar o petróleo (Miles, 2005). Em outros termos, na visão dos operadores locais, na época, tratava-se de uma longa torneira (Elsevier, 2005).

Mesmo sendo uma exploração offshore, ainda não a entendemos como o surgimento de um novo paradigma tecnológico. Tratava-se de uma adaptação rudimentar da tecnologia onshore, que por sua vez representava o paradigma anterior empregado para viabilizar a produção de petróleo em terra. A precariedade do processo decorria de a instalação dos equipamentos e dutos no poço ser realizada por homens que praticavam mergulho livre, pois na época não existiam escafandros e muito menos cilindros de oxigênio. Somente em 1910 a Marinha americana desenvolveu os sistemas de bombeamento de oxigênio (os chamados Scuba = self-contained underwater breathing apparatus). E, no final da década de 1930, em função da Segunda Guerra, a Marinha americana desenvolveu os primeiros cilindros de oxigênio, que rapidamente foram introduzidos na exploração de petróleo. Portanto, a possibilidade do desenvolvimento da tecnologia offshore (que constituiria um novo paradigma) teria de esperar algum tempo até que as condições do ambiente tecnológico se tornassem propícias.

Em função dessas condições paradigmáticas incipientes não foi possível avançar na exploração em mar, que se restringiu a lagos e rios e em profundidades não superiores aos 15 metros. $O$ recorde de distância a partir da terra, alcançado por essa estrutura, foi de quase 400 metros no condado de Summerland (Califórnia) no início de 1897. Esta e outras estruturas tiveram curta duração (1895-1902), porque nesse último ano uma série violen- 
ta de furacões destruiu completa ou parcialmente diversas instalações, o que forçou a migração de parte do investimento em produção de petróleo offshore para outras regiões com menor adversidade climática. Deu-se início ao desenvolvimento de tecnologias específicas offshore (Austin et al., 2004). Isso implicou indícios de mudanças no ambiente tecnológico, com o surgimento de atividades e negócios exclusivamente dedicados à exploração offshore.

A migração dos investimentos ocorreu para a Venezuela, e duas inovações importantes ocorreram a partir disso. A primeira e mais importante, que ocorreu no Lago Maracaibo no final da década de 1920, foi o surgimento de uma plataforma com estacas de madeira presas ao solo que dispensava o uso dos cavaletes. Tratou-se do primeiro processo de produção offshore independente do controle terrestre, mas que ainda não pode ser considerado como o início da trajetória do que viria a ser o sistema rígido de produção, uma vez que não havia sido testado nas condições adversas de águas marítimas (Lankford, 1971, apud Austin et al., 2004). A outra inovação foi o caixão pneumático, uma estrutura retangular de concreto - que contém em seu interior materiais mais leves do que a água do mar (água de lastro ou ar) - entre as pernas da plataforma que serve para facilitar o seu deslocamento (transporte) e sustentabilidade no leito marinho. Esse suporte também foi aperfeiçoado e difundido nos primeiros anos de exploração offshore na zona norte do Mar do Norte, Noruega (Lappegaard et al., 1991).

Mas foi com a migração para o Golfo do México que se estabeleceu uma dinâmica inovadora offshore. É a partir dessa região que se estabeleceu o marco inicial de um novo paradigma, com trajetórias tecnológicas dedicadas, e, conseqüentemente, da produção mundial offshore em escala comercial.

\subsection{A produção offshore no Golfo do México}

A exploração offshore nessa região deve ser entendida a partir da "corrida pelo petróleo" onshore. No início do século, várias foram as descobertas nos Estados de Arkansas, Mississipi, Oklahoma, Flórida e Louisiana, e com o conhecimento da exploração na Califórnia exploradores estenderam o risco para a exploração em campos dentro das praias, lagos, rios e pântanos localizados nesses estados. 
O primeiro poço offshore perfurado e que simbolizou o início da atividade offshore no Golfo do México foi em Caddo Lake/Louisiana, em 1911 (U.S. Departament of the Interior, 2005). Uma maior dinâmica do crescimento dessa forma de exploração relacionava-se ao fato de que ainda se destinava grande parte dos esforços de desenvolvimento tecnológico a campos no interior do estado de fácil acesso, e, obviamente, às condições estruturais do desenvolvimento do ambiente propício. Por exemplo, havia dois entraves tecnológicos e um regulatório: não existiam equipamentos de precisão para detectar os campos submersos e, como já dito anteriormente, as estruturas de exploração eram dependentes do controle terrestre, não existindo uma regulação adequada ao avanço da exploração em águas, uma vez que, no início, a legislação federal contemplava apenas os projetos de exploração em terra e finalizados a poucos metros da praia (McGuire, 2004).

Sobre o primeiro entrave tecnológico, o estado da arte da tecnologia sísmica implicava pouca eficiência, o que exigia a perfuração contínua de uma área até encontrar os pontos de vazão. A única técnica utilizada era o Eötvös Torsion Balance, que media a gravidade do solo terrestre e indicava grosseiramente as possíveis áreas com jazidas de petróleo. No mar aumentava a imprecisão, por conta da mudança atmosférica. Portanto, não havia ainda modelo algum de P\&D inicial que pudesse indicar soluções para as condições mais complexas dos campos marinhos.

Somente durante a Primeira Guerra Mundial surgiu o sismógrafo de refração (refraction seismograph), que veio da Marinha americana, ao se aperfeiçoar o sismógrafo para a busca de submarinos inimigos; já no final da década de 1930 a Golf Oil desenvolveu a sísmica a rádio, que era mais potente. Tratou-se de um tipo de inovação radical, dado que permitiu a detecção mais precisa de grandes reservatórios em águas marítimas mais profundas (além dos 100 metros).

Mas as atividades offshore em mar, mesmo com o avanço nos recursos sísmicos, ainda eram bastante limitadas pela falta de um mecanismo legal que oficializasse e permitisse a produção além da praia. Esse entrave foi dissolvido quando o Senado americano aprovou, em 1937, o projeto do senador Gerald Nye, que declarava que as terras sob o mar próximo da margem costeira deveriam ser incorporadas ao domínio público e, portanto, suscetíveis à exploração. 
Essa alteração institucional, atrelada aos avanços das sísmicas, ampliou consideravelmente a possibilidade de prospecção em águas marítimas no Golfo, mas ainda restringida pela falta de tecnologias de exploração mais sofisticadas, uma vez que a exploração ainda continuava calcada no modelo das plataformas dependentes do controle terrestre.

Ainda em 1938, na cidade de Creole/Louisiana, utilizava-se o sistema de cavaletes aperfeiçoado pelas companhias Pure Oil, Superior Oil e Brown $\&$ Root (empresa de engenharia), que permitiu a exploração de poços até 1.600 metros de distância da costa e em profundidade de até 10 metros (Austin et al., 2004). Tratou-se de um sistema aperfeiçoado porque a sua estrutura resistiu relativamente bem a um grande furacão em 1940, em que os equipamentos danificados, depois de reformados permitiram à estrutura como um todo continuar produzindo petróleo por 30 anos, quando o poço chegou ao seu limite (Offshore, ${ }^{1}$ 1963, apud Austin et al., 2004).

Porém, o aumento das dificuldades do uso de cavaletes em operações mais distantes da costa e as descobertas de novos reservatórios em maiores profundidades do Golfo impuseram a necessidade de se estabelecer uma direção da P\&D relacionada ao segmento offshore. Dois desenvolvimentos importantes iniciais surgiram dessa nova trajetória da P\&D: a solda aquática e o alicate hidráulico, ambos durante a Segunda Guerra (Austin et al., 2004).

As pesquisas tomaram duas direções: plataformas de tamanho grande, com capacidade para estocar petróleo e com maior peso para resistir aos furacões, mas com elevado custo, e plataformas pequenas, mais fáceis de serem montadas e com menor custo. Ambas com uma estrutura independente do controle terrestre. Em 1947, as companhias decidiram por privilegiar a segunda linha de P\&D.

\subsection{Ambiente tecnológico e inovações permanentes}

A primeira plataforma independente da história offshore e que deu início à trajetória SRP foi a Kermac 16, a qual possuía aproximadamente 11,5 por 21,5 metros. Esta foi desenvolvida pelo consórcio de companhias liderado por Kerr-McGee, Humble Oile Phillips Petroleum. Essa plataforma foi instalada a 12 milhas da costa da cidade de Morgan/Louisiana e produzia petróleo em um poço de 6 metros de profundidade, estando presa ao solo marítimo por 16 colunas de concreto e ferro, fixadas até 31 metros dentro do 
solo atlântico. O empreendimento teve um custo inicial de US\$230 mil e durou até 1984, quando se esgotaram as reservas do campo (Miles, 2005). A partir disso é possível identificar dois elementos relativos ao surgimento de um novo paradigma tecnológico que se referem ao desenvolvimento de novos conhecimentos, entre os quais muitos de natureza tácita. Um tratou do projeto do engenheiro Ferdinand Hauber, que integrou o projeto de design no Canal do Panamá e cujos conhecimentos relativos a plataformas foram fundamentais, e o outro foram os conhecimentos disponíveis a partir da plataforma independente do Lago Maracaibo/Venezuela (Miles, 2005; Austin et al., 2004).

Dada a pequena dimensão da plataforma de Kermac, não existia espaço para armazenar petróleo e nem mesmo para a moradia dos trabalhadores. A solução foi criar um mecanismo de evacuação do petróleo para um barco, o qual estaria permanentemente ancorado ao lado da plataforma, e outro barco para servir de moradia. Esses barcos foram todos comprados das Forças Armadas. A embarcação de transporte do petróleo teve poucas adaptações, pois o mesmo já servia para transportar combustível e suprimentos durante a guerra. A partir desse marco inicial, o uso de embarcações para estocar e transportar o petróleo tornou-se uma prática difundida em todos os tipos de plataformas e em todas as províncias de petróleo, recebendo o nome de tender-supported plataform, ou embarcação de suporte às plataformas. ${ }^{2}$ Sobre a embarcação-moradia, esta teve de ser totalmente readaptada, inclusive com a retirada de seus motores (Pratt et al., 1997, ${ }^{3}$ apud Austin et al., 2004). A partir desta trajetória offshore, iniciou-se uma nova corrida pelo petróleo, agora no Golfo, e em apenas cinco anos já havia aproximadamente 70 unidades independentes de diversos tamanhos e alturas - refletindo, no início, o caráter incremental, adaptativo e relativamente aberto das inovações nesse segmento - espalhadas pela província, tendo a Humble Oil como principal player.

A complexidade de exploração do segmento offshore em relação ao clima, força e altura das ondas forçou a busca do conhecimento de caráter mais multidisciplinar, lançando as bases para a formação de um sistema setorial de inovações. Foi a partir do offshore que a indústria do petróleo buscou uma aproximação mais sistemática e intensa com instituições de pesquisa que viabilizaram a criação de cursos de oceanografia e meteorolo- 
gia marítima (especializada em furacões), por diferentes universidades, como as de Berkeley (Califórnia) e do Texas. Já as empresas, para facilitar a comunicação com as instituições de pesquisa, tiveram de criar laboratórios próprios de pesquisa e contratar "oficiais do tempo" (weather officers), exmilitares especializados em previsão do tempo. A liderança dessas atividades cabia ao Instituto de Petróleo Americano (API).

Esse sistema setorial se ampliou a partir das atividades de levantamento liderado pelo API. Entre 1957-1961 esta liderou o Projeto 51, que visava a mapear e criar uma grande base de dados sobre as características geofísicas, climáticas e ambientais do Golfo do México, em que mais empresas e instituições foram envolvidas. Às empresas cabia o papel das atividades práticas, como perfurações, sísmicas, instalação de barômetros, de cilindros sob a água para medir a velocidade das ondas etc., e repassar as informações obtidas para as universidades, institutos de pesquisa e pesquisadores autônomos, a quem cabia, por sua vez, o papel da P\&D. O API exercia o papel de organizar e canalizar as informações e difundir e estimular a geração de conhecimento dentro da indústria do petróleo (Willey, 1953, ${ }^{4}$ apud Austin et al., 2004).

Algumas inovações incrementais importantes surgiram (quadro 1), de forma que, ao longo do tempo e no conjunto, a Humble Oil conseguiu, em 1957, alcançar a exploração de 100 pés (33 metros) de profundidade.

Essas inovações ilustram a forte ênfase dada à $\mathrm{P} \& D$ em torno do segmento offshore. Em função desse intenso avanço tecnológico na década de 1960, a produção offshore chegou aos 127,6 milhões de barris (4,8\% da produção total americana). Nesse período, a Shell já estava se tornando a principal player do Golfo, em função do domínio do maior nível de capacitação, decorrente dos diversos programas de pesquisa desenvolvidos em seus laboratórios, desde o desenvolvimento de embarcações até estudos paleontológicos (Austin et al., 2004).

Entretanto, mesmo em condições naturais adversas decorrentes de uma série de grandes furacões entre 1964 e 1969, em função da path-dependence sustentada pela forte trajetória do SRP, as companhias americanas não conseguiram propor alguma nova plataforma mais adequada. Por outro lado, ainda existiam campos de águas rasas a serem explorados, de forma que a pesquisa, no final da década de 1960, ainda continuava no sentido de ampliar a eficiência do SRP. Em outros termos, por mais que as condições 


\section{Quadro 1: Algumas inovações importantes introduzidas pela P\&D a partir da década de 1960}

\section{Novos produtos dedicados ao segmento offshore}

Novo sistema de ancoragem mais seguro para os barcos das tripulações

\section{Características fundamentais}

Consistiu basicamente na adição de duas ou três novas âncoras em cada embarcação. Posteriormente, deu origem à ancoragem Taut Leg, bastante utilizada em plataformas flutuantes. Taut Leg são diversos cabos fixados em diversos locais que impedem o excessivo deslocamento da plataforma (Austin et al., 2004).

Sistema de perfuração

A mesma embarcação, que anteriormente apenas servia de transporte do sistema de perfuração, foi adaptada para realizar a perfuração.

O conhecimento gerado a partir dessa adaptação gerou um know-how utilizado na fase inicial do desenvolvimento de plataformas flutuantes.

Estrutura de sustentação das plataformas rígidas Os pinos que no início eram introduzidos no solo foram substituídos pelas jack-ups, que são estruturas tubulares que sustentam de forma mais sofisticada a plataforma. Essa nova estrutura de sustentação permitiu a instalação de mecanismos que a partir da força hidráulica possibilitam a auto-elevação da plataforma.

Embarcação de perfuração da Shell Bluewater ${ }^{5}$ Para dar maior estabilidade, possuía um dispositivo que submergia todo o equipamento de perfuração. Permitiu a perfuração e produção em poços de 200 pés a partir de 1965 (Rankin 19866, apud Austin et al., 2004).

Primeira sísmica digital Desenvolvida por um grupo de companhias junto à Universidade do Texas. Essa nova tecnologia dá origem, no início dos anos 1970, à sísmica com imagens em três dimensões.

Tecnologia fundamental a partir da exploração em águas profundas, além dos 400 metros.

de constituição flexível

Várias pequenas plataformas produzem e enviam o petróleo para uma plataforma central. 
climáticas tivessem alterado as expectativas tecnológicas a ponto de se repensar em novas soluções para a exploração offshore, essas soluções se restringiram a um mesmo padrão tecnológico.

Uma nova alternativa somente surgiria em um ambiente de seleção cujas condicionantes seriam totalmente diferentes. Trata-se da descoberta de campos de petróleo submarinos no Mar do Norte (Europa), sendo que a geologia não linear da bacia européia estabelecia campos em águas mais profundas próximos da costa. Portanto, seria necessário um novo sistema de produção, mais adaptado a maiores profundidades. ${ }^{7}$

\section{A PROdUÇÃo de PETRÓleo NO MAR dO NORTE E O DESENVOLVIMENTO DE NOVAS TRAJETÓRIAS TECNOLÓGICAS}

A descoberta de petróleo e gás em Groningen, na costa marítima da Holanda, em 1959, quebrou todas as expectativas vigentes até então sobre a existência de petróleo no Mar do Norte. No entanto, prospecções feitas entre 1962-1963, pioneiramente realizadas pela companhia Phillips Petroleum, confirmaram a existência de petróleo e gás no Mar do Norte; mas as novas pesquisas indicaram que a maior parte das reservas se localizava principalmente nos campos entre o Reino Unido e a Noruega. Desse modo, os governos desses países realizaram um acordo em 1965, permitindo a abertura de licitação desses campos. O acordo dividiu o Mar do Norte em 37 quadrantes, cada um de 15 minutos de latitude e 20 minutos de longitude, tendo uma linha imaginária traçada no meio desses quadrantes e dividindo os campos para os respectivos países. Assim, começaram as licitações e a produção dos campos em ambos os países (Fields in production, 2006).

O Reino Unido possui três vezes mais campos do que a Noruega, mas com um tamanho médio inferior aos encontrados neste último país. Além dessa diferença, os campos gigantes da Noruega formam uma reserva maior de petróleo; já no Reino Unido há uma maior disponibilidade de gás natural, devido a uma diferente constituição geológica dos campos. A reserva norueguesa é um pouco superior à britânica, mas de qualquer maneira ambos os países, devido à produção offshore, tornaram-se auto-suficientes em petróleo. Por intermédio de um dos maiores investimentos realizados pelo setor industrial europeu, o Mar do Norte se tornou uma das maiores pro- 
víncias de petróleo do planeta (Beynon, 2006). Paralelo a isso, as companhias de petróleo e outras empresas de cada um desses países tornaram-se importantes players na exploração de petróleo offshore em todo o mundo.

\subsection{O avanço nos sistemas subsea, sísmicas e tecnologia de perfuração: o crescimento da big tree na Noruega}

A produção no Mar do Norte teve início apenas em 1969, com a descoberta do campo gigante (2,5 bilhões de barris) de Ekofisk, localizado em lâmina d'água de 70 metros. Mas a atividade em escala comercial apenas teve início em 1971, por intermédio de uma plataforma fixa auto-elevatória, operada pela Phillips Petroleum.

Como não existia produção de petróleo na Noruega até então, nenhuma institucionalidade era necessária. Entretanto, em 1971 foi criado um órgão para administrar as operações de petróleo no país, a Norwegian Petroleum Directorate (NPD). O órgão passou a ser responsável por novos leilões e pela regulamentação do setor, que nos primeiros anos foi dominado totalmente por companhias internacionais. Paralelamente a essa inserção de multinacionais do petróleo, foi criada a companhia estatal norueguesa de petróleo e gás natural — Statoil ${ }^{8}$ — a qual passou a ter $50 \%$ ou mais dos direitos de explorar todos os novos campos descobertos na região da Noruega (Norwegian, 2006).

A NPD iniciou os leilões pelos poços localizados em águas rasas, aumentando a profundidade média em cada nova rodada. Um dos motivos desse gradualismo era a estratégia de oferecer um maior tempo de capacitação para a Statoil, permitindo, assim, que ela pudesse competir com as multinacionais, como Shell, Phillips Petroleum, Halliburton etc. As áreas de águas profundas foram colocadas em leilão pela primeira vez apenas na $15^{\mathrm{a}}$ rodada de leasings em 1995.

A Statoil, aparentemente, sofreu rápido e intenso processo de capacitação em tecnologias offshore, pois já em 1976, junto com os fornecedores, conseguiu desenvolver e instalar no Campo de Tommeliten o primeiro sistema subsea na costa norueguesa. Tratava-se de uma iniciativa importante do ponto de vista de novos desenvolvimentos tecnológicos, uma vez que nem mesmo algumas companhias tradicionais do Golfo do México dominavam e operavam tais tecnologias nos EUA. A partir desse empreendimen- 
to inicial, a Statoil se tornou a segunda maior operadora de equipamentos subseas do planeta, atrás apenas da Petrobras (Keilen, 2005).

Nesse processo de capacitação, a Statoil difundiu o uso de plataformas fixas, do tipo jack-up (auto-elevatória) com uma base de concreto (caixão pneumático), semelhante à desenvolvida na Venezuela nos anos 1930-1940. Essa base de concreto, chegando à altura de 50 metros, era projetada para ficar cheia de água de lastro (mais leve) ou ar, facilitando o transporte da plataforma por embarcações (Lappegaard et al., 1991). A escolha dessa plataforma decorre, obviamente, da facilidade de locomoção e da formação comum dos campos noruegueses, que são grandes horizontalmente, mas relativamente pouco espessos. Assim, a nova estrutura impedia que a plataforma afundasse dentro da areia, como aconteceu com plataformas da Shell em 1969. A mais profunda dessas plataformas foi instalada no poço de Gulfaks C a 220 metros (Norwegian, 2006). As empresas holandesas contribuíram fortemente com a Statoil nessa fase inicial, as quais passaram a exercer um importante papel no desenvolvimento tecnológico offshore local e mundial ao longo do tempo. Uma dessas empresas foi a Aker Kvorner, que, além de se especializar na produção da plataforma com caixão pneumático, temse mostrado uma das principais empresas fornecedoras de equipamentos subsea da Petrobras. ${ }^{9}$

Em 1986, visando a uma maior capacitação setorial offshore e à diminuição do uso de tecnologia externa, o governo federal norueguês criou um fundo setorial com base nos royalties gerados na exploração de petróleo para apoiar a P\&D e criar novas empresas e organizações não empresariais orientadas a satisfazerem as necessidades do segmento. Entre as firmas e organizações que passaram a receber apoio financeiro do fundo estão: a Norwegian Academy of Technological Sciences, uma universidade que desenvolveu cursos sobre tecnologias e engenharias offshore; institutos de pesquisa como Petroleum Research e Offshore Media Group (OMG); empresas locais de engenharia, como Vetco, FMC Technologies e a holandesa Aker Kvaerner; além da estatal Statoil, que absorveu quase um quarto dos recursos (Keilen, 2005).

Uma parte desses recursos destinados à Statoil foi utilizada para desenvolver uma importante inovação para toda a indústria offshore: a tecnologia de perfuração horizontal. Essa tecnologia foi desenvolvida para viabilizar a 
exploração de alguns campos da área de Ekofisk, ${ }^{10}$ inviabilizada até então, devido à sua grande amplitude horizontal. ${ }^{11} \mathrm{~A}$ tecnologia foi finalizada em 1991 e rapidamente introduzida em toda indústria, como no Campo de Roncador em 1996 (Keilen, 2005).

Outra importante inovação iniciada nos anos 1990 e ainda em desenvolvimento por empresas norueguesas foi a tecnologia sísmica em $4 \mathrm{D}$, que permite, por exemplo, a visualização do fluxo subterrâneo do petróleo, otimizando os locais de perfuração nos campos gigantes, como o Campo de Troll, de 450 quilômetros quadrados. Esse empreendimento começou a ser desenvolvido no final dos anos 1990 pela empresa. A sísmica 4D, já disponível no mercado, ainda está em processo de maturação devido à sua complexidade, principalmente em relação à modelagem de interpretação dos dados sísmicos. Um importante cliente, transformado em parceiro de pesquisa, foi a Petrobras, que vem apresentando importantes avanços nesta e em outras tecnologias de simulação, principalmente a partir do início deste século (Keilen, 2005).

Em resumo, a contribuição norueguesa para o segmento offshore relaciona-se principalmente às tecnologias sísmicas e de perfuração. Entretanto, muitas das empresas criadas para apoiar as atividades de P\&D na região foram fundamentais para a evolução dos novos tipos de plataformas (novas trajetórias) desenvolvidas na parte sul do Mar do Norte, mais especificamente no Reino Unido. Em última instância, notamos que o desenvolvimento tecnológico que viabiliza as descobertas na Noruega impôs o desenvolvimento das instituições, tanto do ponto de vista das condições de governança, como de mecanismos e gestão e sustentação de um sistema setorial de inovação (a partir dos relacionamentos interfirmas).

\subsection{A produção no Reino Unido e as novas trajetórias tecnológicas}

Em 1969, foi descoberto o primeiro campo de petróleo offshore no Reino Unido, o Campo de Arboath. Em 1971, outros três campos foram descobertos, os de Argyll, Auk e Brent (Keilen, 2005). Para fortalecer a atividade offshore, o governo britânico, como fez o norueguês, criou um fundo de estímulo à pesquisa, onde instituições como o Institute of Geological Sciences, o Institute of Oceanographic Sciences, entre diversos outros laboratórios, como o National Engineering and Science e Engineering Research Council, 
foram beneficiadas (Freitas, 1993). Essas instituições mostraram grande importância para o avanço da viabilidade tecnológica e econômica da exploração de petróleo em águas no Mar do Norte e, conseqüentemente, nas demais províncias offshore existentes no planeta.

O Campo de Argyll serviu como o marco inicial do sistema de produção flutuante (SPF), onde a Hamilton Brothers Oil \& Gas, que operava o campo, instalou a primeira plataforma semi-submersível de produção (SS-FPU) com um Sistema de Produção Antecipado (SPA) em 1975. Essa plataforma, na realidade, era uma embarcação de perfuração adaptada para servir também como unidade de produção. Mas, diante do design triangular e da função única de produção e não-transporte (offshoring), a embarcação foi considerada uma plataforma, e não um barco. Para empregar o novo conceito da plataforma, a operadora do campo contou com o apoio da Kerr-McGee, que possuía o conceito da embarcação de perfuração, a Sedco 135. Esse campo, após produzir cerca de 100 milhões de barris de petróleo, cessou a atividade em 1992, por tornar-se inviável economicamente, mas voltou a funcionar novamente em 2003, com a iniciativa de três empresas: Aberdeen-Based Oil Company, Tuscan Energy e Acorn.

Essa plataforma foi um importante avanço da Hamilton Brothers, uma vez que foi a primeira, e dados o elevado custo e os graves acidentes em outras tentativas, nenhuma outra plataforma flutuante foi instalada e mantida no Mar do Norte até meados da década de 1980. Mas as empresas localizadas na região britânica continuaram a busca de um novo modelo tecnológico mais eficiente do que as plataformas fixas, diante do interesse de ampliar a profundidade da exploração. Assim, em 1984, a companhia de petróleo inglesa Conoco deu início ao SFP quando instalou a Tension Leg Plataform (TLP), no Campo de Hutton, a 148 metros. Esse modelo de plataforma tornou-se um dos mais difundidos em todo o mundo.

A TLP é caracterizada por um sistema de flutuadores (buoyants), semelhante ao da plataforma flutuante, e por uma estrutura de sustentação flexível, não rígida como nas plataformas fixas, mas que também não permite um posicionamento tão dinâmico quanto o das plataformas flutuantes. Esse é, portanto, um modelo híbrido de plataforma. A estrutura de sustentação é a característica mais marcante e complexa desse novo modelo. Geralmente possui quatro grandes colunas, onde estão instalados os flutuado- 
res, e cada uma dessas colunas possui conjuntos de cabos entrelaçados (tendões ou pernas tensionadas) e amarrados ${ }^{12}$ nos templates ${ }^{13}$ localizados no fundo do mar.

Desenvolver esse sistema de ancoragem inédito foi a principal dificuldade da Conoco na concepção da nova plataforma, dado que o conhecimento disponível em flutuadores era insuficiente. ${ }^{14} \mathrm{~A}$ Conoco contou com o apoio de um conjunto de pesquisadores de várias instituições para superar o entrave da ancoragem. Dentre os colaboradores mais marcantes estão alguns pesquisadores do Imperial College, como Riaden e Semnle, ${ }^{15}$ que publicaram um artigo em 1983 sobre o comportamento da tensão de equipamentos axiais, e a Bell Electronics, por sua colaboração no desenvolvimento dos sensores de tensão, além de tradicionais empresas de engenharia, como a norueguesa GVA (Jardine et al., 1988).

Como apresentado em Jardine e Potts (1988, p. 232), a Conoco dividiu o problema a ser resolvido em seis grupos de pesquisa, mostrando o caráter orientado do processo de P\&D. Esses grupos foram: (1) as condições da superfície do solo; (2) a constituição do solo; (3) o processo de instalação do conjunto dos tendões; (4) o equilíbrio após a instalação; (5) a força (resistência) de cada grupo de tendões; (6) o comportamento de todo o sistema. As primeiras duas fases da pesquisa (de estudo do solo) começaram em 1979, e foram detectadas camadas de areia entre a formação rochosa do poço. Com isso, a etapa seguinte foi realizar o "amassamento" do solo. Depois foi o processo de instalação de estacas para fixar os templates a uma profundidade de até 58 metros.

Os templates, onde os tendões foram amarrados, estavam equipados com medidores de tensão conectados a computadores na plataforma. Além desses medidores, outros 200 sensores foram dispostos nos tendões, permitindo ao computador central na plataforma controlar a tensão de cada cabo. Assim, a estabilidade da plataforma seria assegurada pelo constante tracionamento ou relaxamento dos cabos, dependendo do empuxo hidrostático da água na plataforma, mesmo em situações de fortes tempestades e furacões. Tratava-se de uma tecnologia que estabelecia o início de uma nova trajetória em função de que o conceito era fazer a plataforma acompanhar, embora em um limite restrito, o movimento do mar (Jardine e Potts, 1988). 
Os pesquisadores, com relação ao item 6, utilizaram múltiplos instrumentos analíticos ${ }^{16}$ para analisar e determinar o comportamento de todo o sistema, como a tensão, quantidade e disposição dos tendões e dos templates etc. Entretanto, para conseguirem analisar o comportamento como um todo, era necessário a utilização de cálculos não lineares tridimensionais. Mas como estes ainda não eram conhecidos nessa época, foi necessário o uso de complexas aproximações e projeções ${ }^{17}$ matemáticas, exigindo ainda mais da capacidade de codificação do conhecimento dos agentes, no intuito de realizar todos os cálculos. A tarefa parece ter sido realizada a contento, uma vez que a TLP de Hutton, além de nunca ter desabado, formou as bases do conhecimento para as demais companhias desenvolverem suas próprias TLPs. Avançava-se mais ainda em direção à nova trajetória do SFP (Adrezin e Benaroya, 1999).

A instalação da TLP de Hutton serviu como base de experiências e averiguações para a Conoco. Após três anos de testes e estudos, a Conoco instalou sua primeira TLP no Golfo do México, no campo de Julliet, a uma profundidade de 536 metros, tornando-se a líder isolada em profundidade em todo o mundo. Diante do êxito, o modelo apresentado na Offshore Technology Conference (OTC) de 1988 passou a ser difundido na indústria offshore. E em 1994 a Shell instalou a segunda TLP do Golfo, no Campo de Auger. Com o início do uso da TLP no Golfo foi possível alcançar maiores níveis de profundidade. Inclusive, a Shell foi a companhia com o maior número de recordes no avanço da profundidade de prospecção (Albaugh, 2005).

\section{A EVOLUÇÃo dA tRAJETÓRIA TLP NO GOLFO do MÉXICO}

Até o início da década de 1990 a Shell ainda estava presa ao padrão SRP, de forma que em 1991 conseguiu instalar no Campo de Bullwinkle (Golfo) a plataforma rígida mais profunda de todos os tempos. Com um comprimento de 412 metros, a plataforma teve um custo superior a US\$ 1 bilhão. Essa plataforma provavelmente será o ponto mais distante da trajetória iniciada em 1947, com a plataforma de Kermac-16 (custo de US\$230 mil - 6 metros de profundidade), em termos de engenharia e de custos, dado que as plataformas fixas possuem uma escala de custos exponencialmente crescente em relação à profundidade instalada, em um grau bastante superior em 
relação às plataformas flutuantes e flexíveis. Mesmo sendo quase inviável economicamente, a Shell precisava iniciar a exploração rapidamente, sob o risco de perdê-la por questões de direito de exploração adquirido em leilão e preso à trajetória SRP; não possuía alternativa (Furtado, 1996; Albaugh, 2005; Miles, 2005).

Para resolver o problema de capacitação em TLP, a Shell criou, no início de 1990, um grupo de pesquisa formado por um conjunto de pesquisadores da companhia. Esse grupo geral foi organizado de maneira a permitir a formação de diversos subgrupos de acordo com as disciplinas de interesse comum dos pesquisadores, como geologia, engenheiras de reservatório, petrofísica etc. Essa rede de pesquisadores internos responsáveis pela geração, adaptação e difusão do conhecimento em torno de alguns tópicos técnicos ficou conhecida como Tubodudes. Além desse processo de pesquisa interdisciplinar, a Shell também contratava especialistas externos para cada grupo, permitindo, assim, a formação mais consistente do conhecimento (Wenger et al., 2001).

A partir desse grupo de estudos e do conseqüente processo de aprendizado, a Shell conseguiu, em quatro anos, dominar suficientemente o conhecimento necessário para superar os desafios e, conseqüentemente, instalar sua primeira TLP, no Campo de Auger, a 872 metros e a um custo aproximado de US\$ 1,2 bilhão. O êxito do grupo não foi apenas adaptar o conhecimento, mas também gerar novos conhecimentos, pois a TLP de Auger foi um recorde mundial de profundidade. Um exemplo disso é que, diferentemente da plataforma de Hutton (Conoco Company), além das bóias em cada coluna, foi desenvolvida outra bóia (pontoons) interligada às quatro colunas $^{18}$ (Andrezin e Benaroya, 1999).

O conhecimento em TLP dominado pela Shell e fundamentalmente o processo de aprendizado por learning by doing tornaram-na a companhia com o maior número de TLPs no Golfo. Os constantes ganhos de escala na produção e montagem de plataformas permitiram à empresa conquistar em média, entre 1994 e 1999, um novo recorde de profundidade a cada dois anos. Esses recordes fortalecem o caráter do avanço do conhecimento da empresa, pois entre a primeira (Auger - 1994 - 872 metros) e a segunda plataforma (Mars - 1996 - 896 metros), com design e equipamentos bastante semelhantes, a empresa conseguiu reduzir o tempo de construção da 
plataforma, permitindo uma redução de custos de aproximadamente US\$ 120 milhões. Além disso, entre a criação da terceira (Ram-Powell - 1997 980 metros) e da quarta (Ursa - 1999 - 1.225 metros), o tempo foi praticamente o mesmo; porém, a Ursa, com uma profundidade e volume de produção maior, teve praticamente o dobro do tamanho.

No Golfo não foram utilizadas apenas TLPs, mas também plataformas flutuantes, inclusive com recordes de profundidade superiores à TLP. Além das TLPs e das plataformas rígidas, são utilizadas no Golfo as plataformas flutuantes do tipo Spars e FPSOs (Albaugh e Nutter, 2005). Com isso, a evolução dessas estruturas levou a produção offshore em águas profundas, pela primeira vez, a superar a centenária exploração em águas rasas em 1999 (Noia, 2005). Atualmente, a produção offshore americana, bastante concentrada no Golfo, contribui com $27 \%$ da produção total de petróleo do país, por onde são gastos anualmente em exploração e produção aproximadamente US\$ 27 bilhões. Esses valores tornaram o programa offshore americano a maior ação não financeira do mundo (Austin et al., 2004; Marshall, 2005).

\section{A EVOLUÇÃO E DIFUSÃO dA TRAJETÓRIA dAS PLATAFORMAS FLUTUANTES NO BRASIL}

A exploração de petróleo offshore no Brasil teve início em 1968, no Campo de Guaricema, na Bacia de Sergipe, por meio de uma plataforma rígida. Mesmo com a descoberta de novos campos, a atividade offshore tinha pouca relevância dentro da Petrobras, uma vez que a importação do petróleo era muito mais barata, o que, conseqüentemente, travava o crescimento do volume de petróleo produzido nacionalmente. O elevado custo da produção nacional decorria da baixa dinâmica inovadora, dado que os equipamentos eram importados e praticamente sem adaptações que suprissem as necessidades locais. Dessa forma, diante do baixo preço do barril do petróleo (até 1972) em relação ao elevado preço de seus derivados, a decisão de investimento da Petrobras em P\&D era majoritariamente voltada para a área do refino.

A partir de 1973, com as mudanças nas condições ambientais com o primeiro choque de petróleo e o conseqüente aumento no preço, a Petrobras 
iniciou seus gastos em P\&D mais direcionados para atividades de exploração e produção. A principal ação do Centro de Pesquisa da Petrobras (Cenpes) foi aprovar o desenvolvimento de projetos próprios de plataformas do sistema rígido de produção. Os esforços resultaram em três projetos distintos de plataformas fixas com diferentes tamanhos e quantidade de equipamentos. Estas ficaram conhecidas como plataformas de $1^{\mathrm{a}}, 2^{\mathrm{a}}$ e $3^{\mathrm{a}}$ Famílias (Sindipetro, 2006), representando o primeiro exemplo de constituição endógena do conhecimento tipo know-how em exploração de petróleo offshore na Petrobras. No entanto, apesar desse exemplo, a P\&D ainda estava lock-in e, conseqüentemente, path-dependence, exclusivamente na abertura das tecnologias importadas, sem que houvesse ainda uma dinâmica local própria de inovações.

Uma tentativa de alterar esse cenário foi a criação da Superintendência de Exploração e Produção (Supep), com a promessa desta de se especializar no monitoramento de novas tecnologias desenvolvidas no exterior e, com auxílio do Cenpes, desenvolver uma eficiente sistemática de importação/ desempacotamento de tecnologias quando se mostrassem interessantes para a exploração brasileira. A principal ação da Supep, nesse intuito, foi identificar o Sistema de Produção Antecipado (SPA) com o Sistema de Produção Flutuante, instituídos no Mar do Norte em 1975, como soluções para os elevados custos da produção no Brasil, e viabilizar a exploração de campos distantes e profundos. Para melhor se adaptar e difundir esse novo procedimento tecnológico dentro das diversas unidades do Cenpes, a Supep criou o Grupo Especial de Sistema de Produção Antecipada, formado por técnicos de vários departamentos, liderado pelo Departamento de Produção (Freitas, 1993).

O SPA consiste na utilização de embarcações ou plataformas flutuantes de perfuração, em caráter temporário, no intuito de conhecer melhor o reservatório e antecipar a receita através da produção com a perfuração e exploração de um poço piloto. A fase antecipada ou piloto permite antecipar a produção (renda), ao mesmo tempo em que são coletados dados relevantes do reservatório em questão. Dessa forma, a receita antecipada fomentava parte das atividades, ao passo que a coleta de informação indicava a viabilidade econômica da exploração do campo, reduzindo o risco de explorar um campo sem condições comerciais de prospecção. Assim, pode-se caracteri- 
zar o SPA como a antecipação de produção por meio de sistemas pilotos e o desenvolvimento do campo em etapas (Petrobras, 2005).

O SPA foi empregado no Brasil ainda em seu estado embrionário, pois era a segunda vez que estava sendo utilizado na história. Seu uso pioneiro foi em 1977, no Campo de Enchova (Bacia dos Campos/RJ), localizado a 120 metros da lâmina d'água, através de uma plataforma de perfuração adquirida da empresa Kerr-McGee. Em um segundo momento, para a fase de produção permanente, foi instalada uma plataforma de perfuração da Kerr$M c G e e$, convertida para produção. A priori, a fase permanente do SPA deveria ser operada por uma plataforma fixa, mas como o campo localizava-se a mais de $100 \mathrm{~km}$ da costa, dificultando a instalação de uma plataforma fixa, a opção foi pela plataforma flutuante. Essa plataforma de perfuração e produção ficou conhecida como Sedco 135D, por ter sido uma conversão da Sedco 135 da Kerr-McGee (Furtado, 1996; Petrobras, 2005).

O SPA, além de permitir a redução nos custos e o aumento no volume da produção de petróleo no Brasil, trouxe outra conseqüência ainda mais importante para a exploração offshore no país, que foi o início do uso do Sistema de Produção Flutuante através das plataformas semi-submersíveis de perfuração convertidas para a produção. A transformação das plataformas para atuarem como produtoras e não somente como perfuradoras foi realizada pelo Departamento de Projetos Básicos da Petrobras, com o auxílio da empresa GVA (Gotaverken Arendal), uma das parceiras da Kerr-McGee no Mar do Norte, a qual se tornou uma das maiores do mundo em projetos de plataformas semi-submersíveis. A transformação foi feita nos estaleiros nacionais: Verolme, Ishibrás e Mauá (Barbosa, 2004; Petrobras, 2005). Uma vez que, de fato, se iniciavam o uso e o envolvimento de outros agentes importantes da economia nacional direcionados para um projeto tecnológico de relativa complexidade, e dado que a partir disso consolidava-se uma nova trajetória selecionada pela Petrobras/Cenpes, é possível afirmar que surgiam aí as bases fortes de um Sistema Setorial de Inovações no segmento offshore brasileiro.

Dada essa nova dinâmica nacional de inovações aliada à elevação dos preços do petróleo no segundo choque no final da década de 1970, viabilizou-se bastante a produção offshore no Brasil. Dessa forma, nos primeiros cinco anos da década de 1980 a produção em bacias marítimas ultrapassou 
a produção onshore. Entretanto, o aumento na produção foi viabilizado principalmente pelas consecutivas descobertas em poços de petróleo em águas rasas - portanto, ainda explorados por plataformas de estrutura fixa —, próximas à costa fluminense (Furtado, 1996; Petrobras, 2005). Na verdade, os elementos petróleo importado com alto preço e disponibilidade de reservas em águas rasas reforçavam o lock-in na abertura das tecnológicas importadas centradas nas estruturas fixas.

Como se sabe, toda possibilidade de quebra de trajetória surge a partir de eventos inesperados que criam oportunidades tecnológicas relativamente mais rentáveis. Em última instância, trata-se da mudança na composição do grau de importância relativa entre os elementos que compõem o ambiente de seleção. Mais especificamente, o que ocorre são mudanças nas condições de oportunidade que alteram as demais condições relativas ao ambiente. $\mathrm{Ou}$ seja, com a descoberta dos campos gigantes de Albacora (1984), Marlim (1985) e Albacora Leste (1986), com mais de 1,5 bilhão de barris equivalentes de petróleo (BEP) e todos com mais de 400 metros de profundidade, viabilizou-se o início da busca de uma nova trajetória de exploração de petróleo offshore em águas profundas. Em outros termos, o evento das descobertas viabilizou a quebra da trajetória sustentada apenas na abertura de tecnologias importadas (estruturas fixas) e oportunizou o desenvolvimento em bases locais de uma nova trajetória tecnológica. Dada a importância desses novos campos, ${ }^{19}$ torna-se rentável sair do desempacotamento e adaptação tecnológica para uma P\&D em bases tecnológicas totalmente novas, qual seja, tecnologias apropriadas para exploração em águas profundas. Portanto, as novas descobertas mostraram-se atrativas para um nível de desenvolvimento tecnológico além das opções existentes no mercado.

A descoberta dos campos se mostrou um marco dentro da história da Petrobras, pois indicava pela primeira vez a possibilidade de reduzir consideravelmente a dependência do petróleo importado. Entretanto, como as trajetórias se contrapõem e resistem umas às outras, mesmo diante dessa importante oportunidade econômica, não foi nesse momento que a empresa suplantou sua rotina de desempacotamento de tecnologias prontas pela P\&D em busca de novos conhecimentos necessários para o tipo de exploração que se colocava. Havia toda uma conduta institucionalizada e sérias dificuldades operacionais a serem superadas. Ao mesmo tempo, essa conduta 
continuava sendo fortificada pela disponibilidade de reservas em águas rasas e pelo elevado custo do petróleo importado, viabilizando a produção, mesmo que ineficaz.

Um fator externo que forçou definitivamente a empresa a alterar sua conduta em prol da endogenização das inovações ocorreu apenas com o contrachoque da Arábia Saudita em 1986. ${ }^{20}$ O contrachoque fez reduzir os preços do barril do petróleo, exigindo uma imediata redução de custos de produção da Petrobras junto à necessidade de aumento da produção interna; do contrário, a opção pela importação poderia desestimular a produção offshore local se os custos de produção não fossem reduzidos.

Nessa direção, a Petrobras/Cenpes criou um programa de capacitação em tecnologia offshore, o Procap. Por meio desse programa, o Cenpes se tornou responsável pela organização e orientação de um processo profundo de P\&D que vem permitindo o domínio, a geração e a adaptação do conhecimento do segmento offshore de águas profundas. Isso representou uma nova fase no aprendizado da empresa, uma vez que este deixou de ser o simples aprendizado operacional, relativo ao desempacotamento e operacionalização da tecnologia importada, para ser um aprendizado voltado para a endogenização das inovações.

Assim, em face da necessidade de desenvolver a fronteira do conhecimento relativa à atividade de produção de petróleo em águas profundas, a Petrobras deu início ao Procap, com base no Sistema de Produção Flutuante. Esse programa, em 20 anos de existência e três fases, se tornou o principal articulador da companhia na função de prover o avanço na exploração de petróleo em profundidades marítimas cada vez maiores e em condições cada vez mais adversas, a ponto de formar um volume de petróleo prospectado condizente com a auto-suficiência nacional.

\section{OS DEMAIS MODELOS DENTRO DA TRAJETÓRIA DAS PLATAFORMAS FLUTUANTES}

Foram desenvolvidos outros dois modelos de plataformas flutuantes no Mar do Norte: a plataforma em forma de navio, ou FPSO (Floating Production Storage and Offshoring), e a plataforma semi-submersível de produção de formato circular, chamada de SPAR. Ambos os modelos tiveram a parti- 
cipação da Kerr-McGee, tornando-se a principal criadora de tipos de plataformas offshore do mundo, pois, exceto na TLP, teve participação direta na constituição da estrutura dos demais modelos. O FPSO, como no caso da SS-FPU instalada em Argyl, teve o início no Mar do Norte, mas se difundiu mais fortemente no Brasil. A SPAR também é uma plataforma semi-submersível, mas diferente das operadas no Brasil, pois possui uma estrutura tubular, e não quadrangular.

Para o desenvolvimento do FPSO, a Kerr-McGee contou com o auxílio da empresa holandesa IHC-Caland e empresas britânicas do setor offshore. O primeiro FPSO foi criado em 1993 para explorar petróleo na bacia britânica, no Campo de Gryphon. Nesse barco são instalados os mesmos equipamentos das plataformas semi-submersíveis de produção. O diferencial do FPSO é que, além de possuir uma grande capacidade de estocagem, tem a vantagem de navegar grandes distâncias (offshoring). Entretanto, diante de seu design, não é comumente utilizado em mares mais suscetíveis a tormentas, como no Golfo do México. A Petrobras é a empresa com o maior número de FPSOs, tendo inclusive o recorde de profundidade no Campo de Roncador, com o navio Seillean, ao extrair petróleo a 1.820 metros (Houson, 2001; Simmons, 2001; Petrobras, 2005).

A plataforma SPAR, ao contrário do FPSO, foi projetada para servir em mares turbulentos, como no Golfo, devido à sua estrutura circular e tubular. A Ker-McGee, calcada em toda a sua experiência de design de plataformas e com o auxílio da empresa finlandesa CSO Aker Rauma, construiu a primeira SPAR em Mäntyluoto, na Finlândia, em 1994. Essa SPAR foi instalada em 1996 no Campo de Netuno (Golfo), explorando um poço a 538 metros. As demais SPARs foram todas construídas na Finlândia e transportadas até o destino final: Golfo, Malásia, Oeste Africano, entre outras províncias. ${ }^{21}$ Além da Ker-McGee, outras companhias criam ou utilizam essa plataforma, como a British Petroleum, Chevron Texaco e Exxon Mobil. A plataforma está em sua terceira geração (cada vez o cubo cilíndrico é menor) e com o recorde de profundidade de 1.710 metros, alcançado em 2004 no Golfo do México (Bauman, 2001).

Em meio a tantas inovações em que muitas delas foram criadas para serem utilizadas em outras províncias, o Mar do Norte movimentou quase um terço dos investimentos industriais do Reino Unido e Noruega na déca- 
da de 1990. Isso vem permitindo a exploração de 130 campos, responsáveis por mais de 2 milhões de BEP diários, em que desde o início da atividade já foram produzidos mais de 28 bilhões de barris equivalentes de petróleo. Essa atividade gera, apenas para o Reino Unido, uma receita anual média de $\mathfrak{E} 5$ bilhões (Dingwall, 2003).

\section{CONCLUSÕES}

Este artigo apresentou a evolução das alternativas tecnológicas para a exploração offshore. Dessa forma, no processo de busca, as companhias de petróleo, em face das dificuldades relacionadas à profundidade e às adversidades climáticas, desenvolveram três trajetórias tecnológicas.

Como toda nova atividade, a offshore foi marcada pela total ausência de P\&D e por procedimentos de tentativas e erros. Para explorar os campos de águas ultra-rasas no início do século XX, além do emprego ostensivo de equipamentos onshore em detrimento do uso de equipamentos específicos, a atividade offshore mostrou-se fortemente rudimentar.

Em função de que a exploração offshore significou o surgimento de atividades relacionadas totalmente novas, evolução no conhecimento científico e novas formas de empreender a atividade, com base nos elementos teórico-metodológicos expostos na seção 1, apresentamos os elementos estruturais e conjunturais que propiciaram o desenvolvimento de tecnologias que configuraram diversas trajetórias tecnológicas dentro de um mesmo paradigma.

Ao longo de todo o texto apresentamos os fatos que demonstram que o padrão aqui foi a busca de soluções para a exploração offshore, e, conforme estas iam sendo alcançadas, se tornavam-se padrões, como, por exemplo, a estrutura da plataforma rígida de Kernac ou das jaquetas (jack-ups) responsáveis pela auto-elevação da plataforma etc. O problema estava em como explorar petróleo em águas profundas sob as intempéries ambientais. Portanto, era necessário encontrar concepções totalmente novas que tivessem muito pouca relação com o passado (onshore). Em última instância, buscamos apresentar os elementos que definem uma nova estrutura de produção a partir da conjuntura e definem um novo ambiente de seleção. 
As trajetórias do paradigma offshore são representadas pelas três formas que não simbolizam necessariamente a superação de uma em face da outra, pois as três opções continuam em atividade. Isso porque a trajetória do Sistema Rígido de Produção continua em franca utilização nos campos de águas rasas, e os Sistemas Flexível e Flutuante dependem de algumas peculiaridades, como a maior viabilidade das TLP em águas mais agitadas, e, sobretudo, pela escolha das companhias em face das duas opções, pois, genericamente, ambas servem para o mesmo fim.

Mostramos que nos três casos os elementos institucionais foram determinantes, uma vez que a evolução tecnológica foi influenciada pela participação dos governos centrais, principalmente no Mar do Norte, com a criação de fundos setoriais de apoio à pesquisa no Reino Unido e na Noruega. Isso influenciou para que o processo de inovação do setor ultrapassasse as atividades isoladas das firmas, através da composição de redes de parcerias em pesquisa. Essa situação de redes de parceria em busca e seleção de soluções tecnológicas, ao se tornar um procedimento padrão nas atividades offshore, deu início à formação de sistemas setoriais de inovação nas duas províncias analisadas.

\section{NOTAS}

1. Offshore, "First Well in Gulf of Mexico Was Drilled Just 25 Years Ago", october, 1963.

2. Esse tipo de embarcação teve um papel de fundamental importância na aplicação do Sistema de Produção Antecipada, um modelo que foi absorvido e difundido pela Petrobras a partir da década de 1970.

3. PRATT, J. A.; PRIEST T.; CASTANEDA C. Offshore Pioneers: Brown \& Root and the History of Offshore Oil and Gas. Houston: Gulf Publishing Company, 1997.

4. WILleY, M. B. Structures in the Sea. Petroleum Engineer, p. 38-47, nov. 1953.

5. A geração seguinte, a Bluewater II, já não era uma embarcação adaptada, e sim construída originariamente para perfuração.

6. RANKIN, J. Untitled Manuscript on the History of Federal OCS Leasing. 1986.

7. Mesmo com todas as intempéries climáticas e não tendo alternativa tecnológica, a solução ainda seria a instalação do SRP, de tal forma que em 1965 o número de plataformas ultrapassou o marco das 1.000 unidades, a Shell conseguiu dois novos recordes de profundidade próximos dos 300 pés (100 metros) e a produção offshore alcançou a produção de 350 milhões de barris, que correspondia a 9\% da produção de petróleo americana. Outras melhorias dentro da trajetória SRP continuaram a ocorrer, como, por 
exemplo, a injeção de argila em alguns locais para permitir uma melhor sustentação das plataformas, e maior intensidade do uso de computadores, de forma que o avanço cibernético contribuiu fortemente para a criação das sísmicas em três dimensões em 1973 (Austin et al., 2004).

8. A Statoil foi privatizada no início de 2001.

9. Além de fornecedora da Petrobras, a Aker Kværner é uma das parceiras da companhia brasileira no projeto do PROCAP 3000 de criação de uma plataforma brasileira, a MONO BR.

10. Campos de Cod, Central Ekofisk, West Ekofisk Albuskjell, Eldfisk, Edda, Embla e Tor (Fields in production, 2006).

11. Além da amplitude horizontal, a perfuração horizontal ampliou a viabilidade econômica da exploração de campos constituídos por diferentes rochas, onde algumas destas, por serem mais sólidas do que outras, serão mais facilmente perfuradas diante da alteração do sentido da perfuração, até a posição horizontal.

12. Na indústria marítima, o termo amarração é utilizado para designar todo procedimento de conexão, de solda e outras situações de interligação de equipamentos e peças.

13. O template é uma base de metal instalada no leito marinho, onde são instalados ou fixados equipamentos, peças e cabos utilizados nas operações de exploração e produção. No caso das TLPs, os templates, além de servirem como a base dos equipamentos, também servem de apoio para a ancoragem.

14. Era um conhecimento que estava apenas parcialmente difundido desde 1975, a partir da criação da plataforma submersível de Argyl.

15. RIADEN, W. J.; SEMNLE. R. M. Design and installation of the Magnus foundations: prediction of pile behaviour. Design in offshore sfructures. p. 37-52, 1983.

16. Como Lagrange, simulação Monte Carlo, matrizes jacobianas e teoremas matemáticos (Jardine e Potts, 1988; Adrezin e Benaroya, 1999).

17. Uma importante externalidade decorrente desse avanço no conhecimento matemático foi a aplicação da mesma metodologia empregada pela Conoco para diagnosticar o motivo dos rápidos momentos de vibração que ocorriam nas estruturas das plataformas auto-elevatórias, o que acarretou algumas modificações estruturais.

18. Cada coluna dessas possui três conjuntos de tendões, cada qual com 12 cabos de aço de 66 centímetros de diâmetro cada.

19. Essas descobertas trouxeram uma importante alteração na disposição das reservas de petróleo no Brasil, pois, a partir de então, mais de 50\% das reservas comprovadas estavam em campos offshores de lâmina d'água além dos 400 metros (Furtado, 1996).

20. O contrachoque foi provocado pela Arábia Saudita, o maior produtor/exportador de petróleo do mundo, em 1986, elevando sua produção a um nível que fez reduzir o preço do barril do petróleo em mais de 20 dólares em poucos meses, pois quis punir os demais membros da OPEP que desrespeitaram um acordo interno da organização (Pertusier, 2004).

21. Não existe SPAR no Brasil. 


\section{REFERÊNCIAS BIBLIOGRÁFICAS}

ADREZIN, R.; BENAROYA, H. Non-linear stochastic dynamics of tension leg platforms. Journal of Sound and Vibration, v. 1, n. 220, p. 27-65, 1999.

ALBAUGH, E. K.; NUTTER, T. 2005 Deepwater solutions \& Records for concept selection: going deeper with production technology. Offshore Magazine, special issue, 4p., dez. 2005.

AUSTIN, D. B.; CARRIKER, T.; MCGUIRE J.; PRATT, T.; PRIEST, A. G. History of the offshore oil and gas industry in southern Louisiana: interim report. Papers on the evolving offshore industry. U.S. Dept. of the Interior, Minerals Management Service, Gulf of Mexico OCS Region, Nova Orleans, L.A., v. 1, 98p. 2004.

BAPTISTA, M. A. C. Política industrial: uma interpretação heterodoxa. IE/Unicamp, 2000.

BARBOSA, R. Plataformas offshore ontem, hoje e amanhã. Brasil energia online. Artigo publicado em abr. 2004. Disponível em: <http://www.brasilenergia.com.br/index.php $>$. Acesso: jan., 2006.

BAUMAN, S. Spar sailaway. Endeavors: Kerr-McGee Magazine, third quarter, p. 8-10, 2001.

BEYNON, R. C. What can the North Sea teach the world. Disponível em: <http://www.examconsultants.co.uk/publications/What $\% 20$ the $\% 20$ North $\% 20$ Sea $\% 20$ can $\% 20$ teach $\% 20$ the\%20World.pdf_>. Acesso em jan., 2006.

DINGWALL, B. Raising the game, realizing the potential. Offshore Europe Revew. Palestra proferida por Bruce Dingwall em "Offshore Europe 2003: Oil \& Gas Exhibition \& Conference”, Fleming Auditorium, Londres-UK, 7p., 2 set. 2003.

DOSI, G. Technological paradigms and technological trajectories: a suggested interpretation of the determinants and directions of technical change. Research Policy, Amsterdam, v. 11, n. 3, p. 147-208, jun. 1982.

ELSEVIER. Offshore pioneers: brown \& root and the history of offshore oil and gas. Elsevier bookstore. Disponível em: <http://www.elsevier.com>. Acesso: jun. 2005.

FIELDS IN PRODUCTION. Disponível em: <http://www.dep.no/filarkiv/204691/FactsOG1204. pdf>. Acesso: jan. 2006.

FREITAS, A. G. Capacitação tecnológica em sistemas de produção para águas profundas, 180 p. (Dissertação de Mestrado) Furtado, A. T. (orientador). Unicamp, 1993.

FURTADO, A. T. La trayectoria tecnológica de Petrobras en la producción costa afuera. Revista Espacios, v. 17, 1996.

HOUSON, C. Pipers play, corks pop. Endeavors: Kerr-McGee Magazine. Third quarter. p. 1-3, 2001.

JARDINE, R. J.; POTTS, D. M. Hutton tension leg platform foundations: prediction of driven pile behaviour. Géotechnique, v. 38, n. 2, p. 231-252, 1988.

HIGHT, D. W; MCINTOSH, W. G. Hutton tension leg platform foundations: measurement of pile group axial load-displacement relations. Géotechnique, v. 38, n. 2, p. 219230, 1988. 
KEILEN, H. (Ed.) Norwegian Petroleum Technology: a success story. Livro publicado por Norwegian Academy of Technological Sciences e Offshore Media Group: NTVA, Trondheim-Noruega, 2005. 98p.

LANKFORD, R. L.; DRILLING M. In: BRANTLY, J. E. (Ed.). History of Oil Well Drilling. Houston: Gulf Publishing, 1971.21p.

LAPPEGAARD, O. T.; SOLHEIM, B. J.; PLUMMER, F. B. Snorre project strategies and status. Paper OTC 6626, apresentado na $23^{\mathrm{a}}$ Conferência Anual da Offshore Technology Conference. Houston: Texas, maio. 1991.

MARSHALL, J. A call to action for the offshore industry. Offshore Magazine. 2p., maio, 2005.

MCGUIRE, T. History of the offshore oil and gas industry in southern Louisiana: An oral history of the development of the oil and gas industry - Interim report. Papers on the evolving offshore industry. U. S. Dept. of the Interior, Minerals Management Service, Gulf of Mexico OCS Region, New Orleans, LA, v. 2, 148p., 2004.

MILES, L. Offshore Pioneers: hermans and George Brown sought adventure through engineering. Insight Magazine: Process, Power \& Marine. Disponível em: <http://www.intergraph.com>. Acesso: nov. 2005.

NOIA. History of Offshore. National Ocean Industries Association. Disponível em: <http:// www.noia.org/membersonly/currentissues/default.asp>. Acesso: nov. 2005.

NORWEGIAN. Oil history in brief. Disponível em: <http://odin.dep.no/filarkiv/204702/FactsOG0104.pdf>. Acesso: jan. 2006.

PERTUSIER, R. R. Sobre a eficácia da OPEP como cartel e de suas metas como parâmetros de referência para os preços do petróleo. (Dissertação de Mestrado), Almeida, E. F. (orientador), Instituto de Economia da Universidade Federal do Rio de Janeiro, 2004.

PETROBRAS 30 years of deep water technology. Petrobras Magazine: International Communications, 77 p., jun. 2005.

SIMMONS, M. R. IRO jubilee: celebrating 30 years of offshore success. Texto apresentado na celebração de 30 anos de empresas holandesas no segmento offshore: IRO JUBILEE, Holanda, Amsterdã, 9 p., nov. 2001.

SINDIPETRO. Histórico da atividade offshore no Brasil. Disponível em: $<$ http://www.sindipetroce.org.br/Ind\%FAstria\%20do\%20Petr\%F3leo/No\%20Brasil/Hist\%F3rico $\% 20$ da\%20atividade\%20offshore\%20no\%20Brasil.htm>. Acesso: jan. 2006.

U. S. DEPARTMENT OF THE INTERIOR. Gulf of Mexico Region: Environmental Information. Minerals Management Service. Disponível em: <http://www.gomr.mms.gov/index_common.html>. Acesso: nov. 2005.

WENGER, E.; MCDERMOTT, R.; SNYDER, W. The early stages of development: planning and launching communities. Cultivating Communities of Practice: a guide to managing knowledge. Harvard Business Scholl Press, Harvard-MA, cap. 4, 13 p., 2001. 